\title{
A review of EPI progress in Pakistan towards achieving coverage targets: present situation and the way forward
}

\author{
Q. Hasan, ${ }^{7}$ A.H. Bosan ${ }^{2}$ and K.M. Bile
}

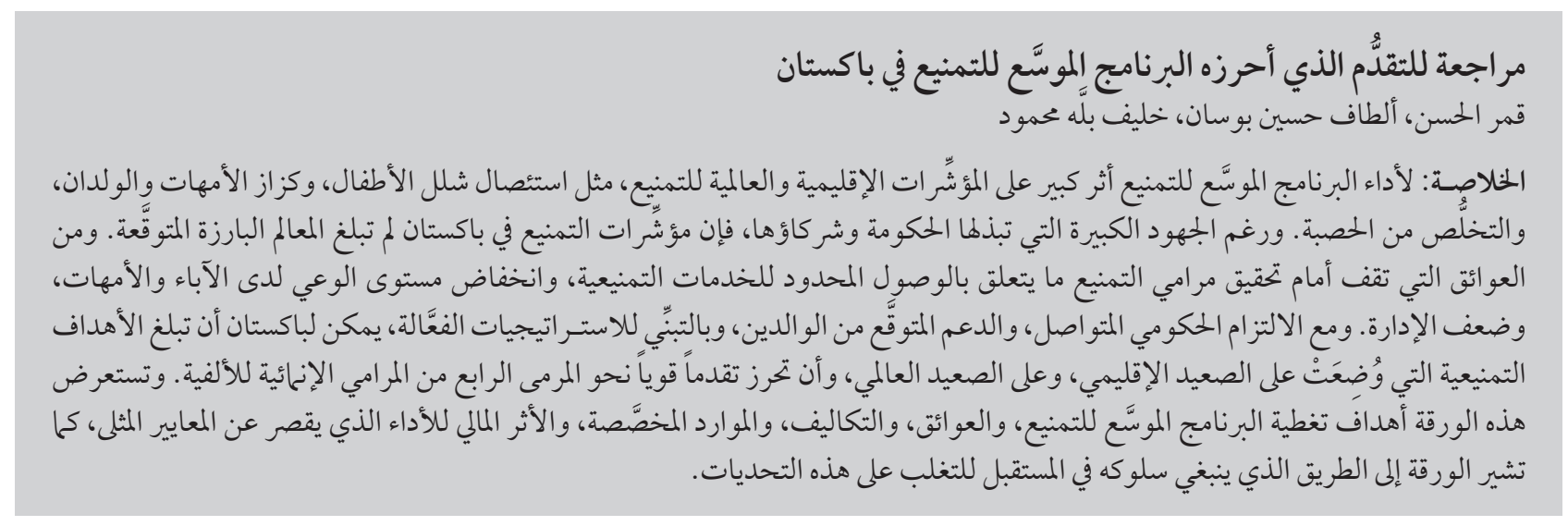

ABSTRACT Pakistan's Expanded Programme on Immunization (EPI) performance has a significant impact on global and regional immunization indicators such as poliomyelitis eradication, maternal and neonatal tetanus and measles elimination. Despite significant efforts by the Government and partners, Pakistan's immunization indicators have not met the expected benchmarks. Barriers to achieving immunization goals are related to limited access to immunization services, lack of parent awareness and weak management. With sustained Government commitment, predictable partner support and by adopting effective strategies, Pakistan can achieve the immunization targets set at the regional and global level and make strong progress towards achieving Millennium Development Goal 4. This paper reviews EPI coverage targets, constraints, costs and resource allocation, and financial impact of suboptimal performance, and indicates the way forward to overcome these challenges.

Examen des progrès du Programme élargi de vaccination au Pakistan vers la réalisation des cibles de couverture : situation actuelle et voie à suivre

RÉSUMÉ Les résultats du Programme élargi de vaccination au Pakistan ont des répercussions importantes sur les indicateurs de vaccination mondiaux et régionaux, ainsi que sur l'éradication de la poliomyélite et l'élimination du tétanos maternel et néonatal et de la rougeole. Malgré les efforts importants du gouvernement et de ses partenaires, les indicateurs de vaccination du Pakistan n'ont pas atteint les niveaux escomptés. Les obstacles à la réalisation des objectifs de vaccination sont l'accès limité aux services de vaccination, le manque de sensibilisation des parents et la faible capacité de gestion. Avec un engagement gouvernemental durable, I'appui prévisible de partenaires et l'adoption de stratégies efficaces, le Pakistan peut atteindre les cibles de vaccination définies aux niveaux mondial et régional et progresser fortement vers la réalisation de l'objectif 4 du Millénaire pour le développement. Cet article examine les cibles de la couverture par le Programme élargi de vaccination, les contraintes, les coûts et l'allocation des ressources, ainsi que les conséquences financières de résultats perfectibles. Il indique la voie à suivre pour surmonter ces obstacles. 


\section{Introduction}

The Expanded Programme on Immunization (EPI) in Pakistan annually targets around 5.8 million children aged below 1 year to protect against 8 vaccine-preventable diseases and 5.9 million pregnant women to protect them and their newborns from tetanus through routine immunization services. The overall objective of EPI is to reduce mortality and morbidity resulting from the 8 EPI target diseases.

EPI is almost the exclusive provider of immunization service in Pakistan, where the private sector provides approximately $3 \%$ of immunization injections [1]. It delivers immunization services through more than 6000 fixed centres and over a million outreach and mobile vaccination sessions annually, involving more than 10000 vaccinators including paramedics trained in EPI, 6000 lady health visitors (LHVs) and other paramedics. Approximately 100000 lady health workers (LHWs) also assist in routine and supplementary immunization activities by social mobilization, defaulter tracing and occasionally providing vaccination. The current routine immunization schedules for children and pregnant women are described in Tables 1 and 2.

EPI began in Pakistan in 1976 on a pilot scale and was expanded countrywide by 1978. Annually, the programme procures vaccines for approximately 5.8 million children and 5.9 million pregnant women [2]. In addition, a large

\begin{tabular}{|c|c|}
\hline Vaccination & Schedule \\
\hline TT-1 & During the first pregnancy \\
\hline $\mathrm{TT}-2$ & 1 month after the first dose \\
\hline TT-3 & 6 months after the second dose \\
\hline TT-4 & 1 year after the third dose \\
\hline $\mathrm{TT}-5$ & 1 year after the fourth dose \\
\hline
\end{tabular}

number of children and women are also targeted to receive immunization through different supplemental immunization activities. Initially started with 6 antigens, the programme added 2 new antigens, hepatitis B and Haemophilus influenzae type $b(\mathrm{Hib})$, during the last decade. Over 30 million children are targeted for every round of polio supplemental immunization activities. Over 3.4 million women of childbearing age were vaccinated with 3 doses of TT vaccine during 2009.

At present, interruption of polio transmission, elimination of measles and neonatal tetanus along with reaching high routine immunization coverage are the main priorities for EPI Pakistan. In the recent past, the programme introduced new vaccines and technologies, which created more interest and parental awareness of immunization. This was reflected in a slow but steady rise in different coverage indicators assessed by independent organizations (Figure 1) [3]. However, these achievements were inadequate to reach the country's goal for polio eradication, measles and neonatal tetanus elimination and did not match the efforts and resources allocated for the purpose by the Government and partners.

The objective of this review is to explore the progress of EPI Pakistan in terms of coverage of different antigens, current knowledge about the constraints to achieving the desired level of coverage, cost and resource allocation, financial impact of suboptimal performance and the way forward to overcome the challenges in attainment of its goals.

\section{Sources}

Several Government documents, survey reports and unpublished programme documents were reviewed and online searches were made to find literature on EPI Pakistan in websites of the World Health Organization (WHO), United Nations Children's Fund (UNICEF) and other sources. The EPI programme's official database along with Government financial documents were also analysed to estimate costs and impact of suboptimal performance.

\section{Results}

WHO and UNICEF had been estimating the country's immunization coverage every year using the country's official reports and the available independent survey data (Figure 1) [3]. In the mid1980s, EPI coverage with 3 doses of diphtheria-pertussis-tetanus (DPT3) vaccine had been around $30 \%$ and with 1 dose of measles vaccine (measles1) had been around $40 \%$. Coverage with both 


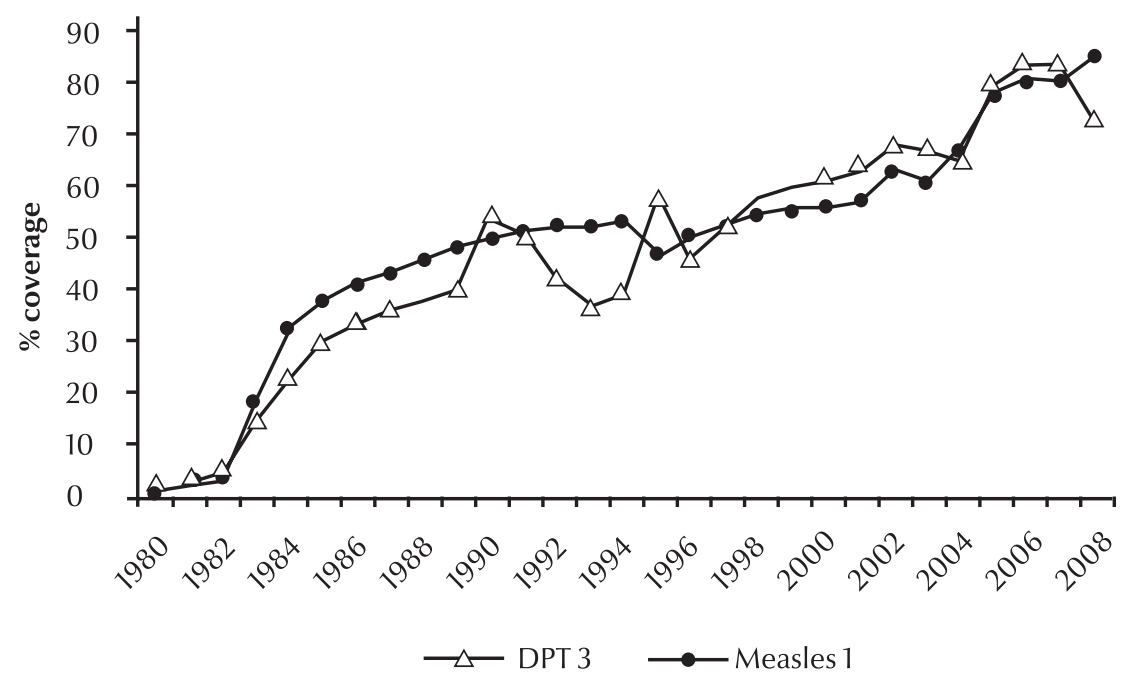

Figure 1 WHO-UNICEF joint estimate of Pakistan national coverage of 3 doses of diphtheria-pertussis-tetanus (DPT3) and 1 dose of measles (measles 1), 1980-2008

vaccines reached $50 \%$, or above, for the first time in 1990. Coverage remained below $80 \%$ for a decade and a half. However, DPT3 and measles 1 coverage reached the $80 \%$ benchmark for the first time in 2005 and 2006, respectively, and remained at $80 \%$ until 2007. In 2008, DPT3 coverage dropped to $73 \%$; however, the official programme database indicates that DPT3 coverage bounced back to $85 \%$ in 2009 and measles 1 coverage remained at $80 \%$. Whereas in 2008 , only $30 \%$ of the districts attained $80 \%$ coverage for DPT3, by 2009 this figure had increased to $61 \%$. Similarly, the proportion of districts that attained $80 \%$ or more coverage for measles 1 increased from 46\% in 2008 to $54 \%$ in 2009.

Fully immunized child coverage was determined through different surveys conducted during the 1995-2007 period (Table 3). A "fully immunized child" means a child who received at least 1 dose of Bacille Calmette-Guérin (BCG) vaccine, 3 doses of oral polio vaccine (OPV), DPT3 and measles 1 vaccine. Over this 1 decade, according to all surveys, the fully immunized child coverage ranged between $47 \%$ and $57 \%$ with an exception in the Pakistan Social and Living Standard Measurement Survey 2004-2005 [4], which reflected a higher achievement. While Punjab came out as the best performing province, Balochistan's achievement remained at the lowest, except in the Pakistan Integrated Household Survey 1995-1996 [5]. The most recent data in the EPI Coverage Evaluation Survey 2006 [1] and Pakistan Demographic and Health Survey 2006-2007 [6] indicated only half of the target children were fully immunized with all antigens.

The key reasons for the Pakistan EPI not achieving the targets have been identified in different studies (Table 4). In spite of numerous successes, such as the addition of new vaccines and raising coverage to over $80 \%$, EPI is still struggling to reach its polio eradication, measles and neonatal tetanus elimination goals. Inadequate service delivery, which leads to irregular access and poor service utilization, was found to be the key reason for this poor performance. The long distance to EPI centres, unaffordable cost to reach the centres, and unavailability of vaccinators and outreach services were found to be the main reasons for limited access to the

\begin{tabular}{|c|c|c|c|c|c|c|}
\hline \multirow[t]{2}{*}{ Surveys } & \multirow[t]{2}{*}{ Year } & \multirow{2}{*}{$\begin{array}{c}\text { Pakistan } \\
\text { (\%) }\end{array}$} & \multicolumn{4}{|c|}{ Province } \\
\hline & & & $\begin{array}{c}\text { Punjab } \\
(\%)\end{array}$ & $\begin{array}{l}\text { Sindh } \\
(\%)\end{array}$ & $\begin{array}{c}\text { NWFP/FATA } \\
(\%)\end{array}$ & $\begin{array}{c}\text { Balochistan } \\
\text { (\%) }\end{array}$ \\
\hline \multirow[t]{3}{*}{ Pakistan Integrated Household Survey [5] } & 1995-1996 & 47 & 49 & 45 & 40 & 60 \\
\hline & 1998-1999 & 55 & 62 & 39 & 57 & 55 \\
\hline & 2001-2002 & 57 & 63 & 46 & 59 & 38 \\
\hline \multirow[t]{2}{*}{ EPI cluster surveys } & 2001 & - & - & 57 & 68 & 50 \\
\hline & 2003 & - & 66 & - & - & - \\
\hline \multicolumn{7}{|l|}{ Pakistan Social \& Living Standards } \\
\hline Measurement Survey [4] & 2004-2005 & 77 & 84 & 73 & 76 & 62 \\
\hline EPI Coverage Evaluation Survey [1] & 2006 & 57 & 76 & 60 & 52 & 32 \\
\hline Pakistan Demographic \& Health Survey [6] & 2006- 2007 & 47 & 53 & 37 & 47 & 35 \\
\hline
\end{tabular}

aUNICEF Pakistan. Coverage Evaluation Survey, Sindh, Balochistan, NWFP \& FATA 2001 and UNICEF Pakistan/Director General Health Services Punjab. Coverage Evaluation Survey - Punjab 2003.

NWFP/FATA = North West Frontier Province/Federally Administered Tribal Areas. 
service. The EPI Coverage Evaluation Survey 2006 [1] indicated that $12.6 \%$ of mothers' reasons for failing to immunize their children was "the vaccination centre is too far or the vaccinator was absent". Distance to the health centre was again highlighted in a recent study undertaken by EPI with the assistance of UNICEF in 2009, as 30\% of mothers reported that it was difficult or very difficult to reach the nearest health facility from their place of residence [7].

Approximately 6000 EPI fixed centres in the country ( 1 centre for about 27000 population) provide immunization services to the people. However, these are not uniformly distributed. One in every 10 union councils (UCs) in Punjab province, the most populous province and recognized as having the most developed infrastructure, is without any EPI fixed centre. While at least 2 vaccinators are required in each $U C$ according to the national EPI policy, the real number is lower (1.3 per UC). Except in Sindh (115\%), all provinces had a much lower number of vaccinators than required according to the national policy. Proportions of vaccinators available against the standard were $52 \%$, $70 \%$ and $72 \%$, in Punjab, Khyber Pakhtunkhwa and Balochistan provinces, respectively. Though some paramedic cadres such as LHVs are engaged in vaccination in some areas, other potential resources, especially trained LHWs, are restrained from providing vaccination independently.

Lack of recipient awareness about the immunization service and its benefits was found to be the second most common contributing factor for low coverage. The Coverage Evaluation Survey - Punjab 2003 [8] highlighted that parental lack of awareness about the need for vaccination was one of the most important reason for low coverage in Punjab. The EPI Coverage Evaluation Survey 2006 [1] supported this finding; lack of awareness about the need for immunization and the need for subsequent doses were the most commonly given reasons ( $18 \%$ and $10.2 \%$, respectively) by mothers for failing to immunize their children.

The total routine immunization cost in 2008 was more than US\$ 104 million. Over half of that total was used to procure vaccines (Table 5). Per child vaccination cost up to DPT3 was compared at actual coverage achieved in the same year against different levels with a gradual increment up to $100 \%$ coverage. According to the $\mathrm{WHO}_{-}$ UNICEF Joint Reporting Form 2008, Pakistan [9], only $73 \%$ target children received all antigens up to DPT3 out of total 5830739 surviving infants. If all intended target children had received at least 3 doses of DPT vaccine, per child expenditure in that year would have been US\$17.89. But according to the baseline year (2008) data of the EPI Comprehensive Multiyear Plan 2011-2015, this expenditure was US\$24.51, which is $37 \%$ higher [10]. This accounted for a total loss of value of routine immunization investment in 2008 equivalent to US\$28 164774.

The Government of Pakistan and other international partners [e.g. Canadian International development Agency (CIDA), Department for International Development [DFID], Global Alliance for Vaccine and Immunization (GAVI), Japan International Cooperation Agency (JICA), Rotary International, UNICEF, United States Agency for International Development (USAID), WHO and World Bank] showed their interest and commitment for the immunization programme by investing sizeable resources over the past years. The Government of Pakistan procures all necessary vaccines and injection equipment for the programme with its own resources except for a share of the pentavalent vaccine, which is supported by GAVI under a cofinancing agreement. The total cost of the current five-year plan (PC-1) for 2009-1010 to $2013-1014$ is PKR 26.422 billion (approximately US\$322 million) [2], which is almost 2 times larger than the

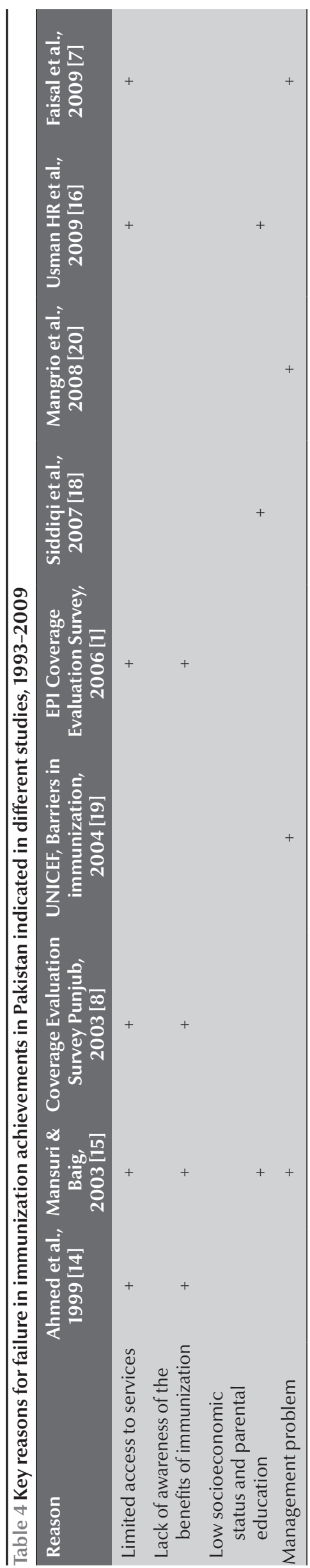




\begin{tabular}{|c|c|c|c|c|c|c|}
\hline \multirow[t]{2}{*}{ Expenditure categories } & \multirow{2}{*}{$\begin{array}{c}\text { Total } \\
\text { expenditure in } \\
2008 \text { (US\$) }\end{array}$} & \multicolumn{5}{|c|}{ Cost per child (US\$) } \\
\hline & & $\begin{array}{c}\text { At actual } \\
\text { coverage } \\
(73 \%)\end{array}$ & $\begin{array}{l}\text { If } \mathbf{8 0} \% \\
\text { coverage } \\
\text { achieved }\end{array}$ & $\begin{array}{l}\text { If } 85 \% \text { coverage } \\
\text { achieved }\end{array}$ & $\begin{array}{l}\text { If } 90 \% \text { coverage } \\
\text { achieved }\end{array}$ & $\begin{array}{l}\text { If } 100 \% \\
\text { coverage } \\
\text { achieved }\end{array}$ \\
\hline Vaccines & 57714408 & 13.56 & 12.37 & 11.64 & 11.00 & 9.90 \\
\hline Injection equipment & 3894360 & 0.92 & 0.83 & 0.79 & 0.74 & 0.67 \\
\hline Operations & 42705209 & 10.03 & 9.16 & 8.62 & 8.14 & 7.32 \\
\hline Total & 104313977 & 24.51 & 22.36 & 21.05 & 19.88 & 17.89 \\
\hline \multicolumn{2}{|c|}{$\begin{array}{l}\text { Loss of value of annual expenditure due to } \\
\text { low coverage (US\$ million) }\end{array}$} & 28.16 & 20.86 & 15.65 & 10.43 & Nil \\
\hline
\end{tabular}

last PC-1 of 2004-2005 to 2008-2009

[11]; $80 \%$ of the planned cost of the current PC-1 will be from the Government's own exchequer. The rise in contribution towards EPI by provincial governments has also been noted. Sindh provincial government budget for EPI increased up to $400 \%$ and $155 \%$ during the last 2 fiscal years, respectively. Being one of the largest international immunization partners, the total GAVI commitment to EPI Pakistan during 2001-2012 was worth US\$313 million (Table 6).

\section{Discussion}

After long slow progress in the initial two decades, DPT3 coverage has started to show a slow but steady rise since the late 1990s [3]. The addition of hepatitis $B$ vaccine to the immunization programme at the beginning of the new millennium failed to boost the coverage as expected. Parents were less compliant to accept 2 injections simultaneously for their infants [1]. Compliance was increased with the introduction of the tetravalent vaccine (DPT-hepatitis B) in 2006, which required only 1 shot for 4 antigens.

The programme faced another setback in 2008 during the addition of another new vaccine, a combination pentavalent form (Hib-hepatitis BDPT), which replaced the then existing tetravalent (DPT-hepatitis B) vaccine. Unfortunately, due to delay in registration and supply of the new product, the introduction could not be timely initiated with the result that a total stock out of vaccine occurred for some months and this was the most likely cause of

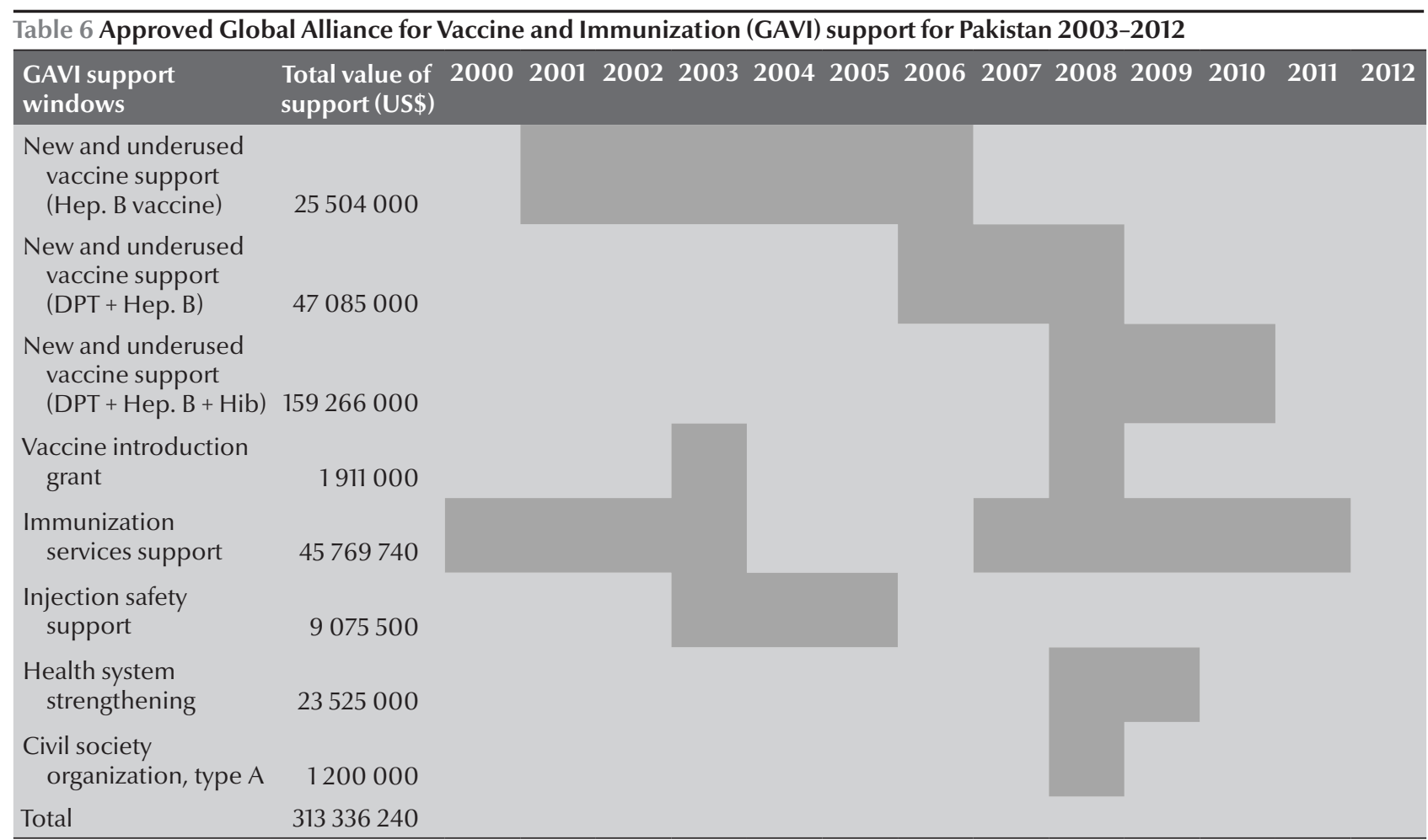

Hep. $B=$ hepatitis $B ; D P T=$ diphtheria-tetanus-pertussis; Hib=Haemophilus influenzae type $b$. 
the fall in DPT3 coverage to $73 \%$ in that year. The vaccine stock out was indicated as the key reason for this drop in DPT3 coverage as a similar drop in coverage was not observed for other antigens, such as BCG and measles 1, in the same year [3]. By early 2009, the new vaccine introduction was complete throughout the country and DPT3 coverage returned to a level above $80 \%$ $[12,13]$.

However, the fully immunized child coverage is still far behind the optimum. In spite of the high coverage claimed in the administrative reports, all surveys except the Pakistan Social and Living Standard Measurement Survey 2004-2005 conducted during 1995 to 2007 to assess immunization coverage in Pakistan indicated that only around half of the targeted children were fully immunized $[1,4-6,8]$. The discrepancy between the reported data and independent assessments raised concerns about the data quality of administrative reports among different stakeholders. Discrepancy in provincial performance was also evident in these surveys. Keen monitoring of the data quality at different level on a regular basis using the standard WHO Data Quality Self-assessment tool may help improve this area.

The most common cause for the poor performance of EPI Pakistan, revealed through a series of studies, was the limited access to the immunization service $[1,7,8,14-16]$. Contrary to the national policy [17], about one-third of UCs did not have fixed centres and the same proportion of government health facilities did not provide EPI services as revealed in different national and subnational programme reviews. Moreover, many fixed centres provided immunization service only once or twice a week. With limited services through fixed centres, the only alternative to access the intended target population was through outreach vaccination sessions, which were again irregular and not well implemented because of limited human resources, inadequate operational support and weak monitoring and supervision. Daily provision of immunization services from all Government health facilities would significantly raise access.

An inadequate number of vaccinators was one of the main reasons for limited access to service $[7,15]$. In an average-sized UC with a population of 25000 , a vaccinator working for 16 days every month would require to make only 18-26 contacts each day. However, due to the wide geographical dispersion of this target population the task is more challenging. Moreover, the unequal distribution of vaccinators has left a significant proportion of the UCs uncovered. This inadequacy could be overcome by using EPI-trained LHWs for delivering vaccination services. As LHWs are embedded in, and well accepted by, the community, they have substantial potential for enhancing EPI coverage in their catchment area. Around 20000 LHWs are ready to provide vaccination after completion of a 6-month training course on routine immunization, assisted by WHO with GAVI health system strengthening (HSS) support. Redistribution of vaccinators in UCs along with use of trained LHWs in immunization service provision could be proven a very effective and immediate measure and would not incur additional cost.

Lack of information about immunization was another key reason for not utilizing the available service $[1,8,14$ 17]. Earlier studies indicated that lack of awareness among mothers about the benefits of vaccination was one of the most important reasons for failing to vaccinate a child; however, a recent studyrevealed evidence ofimprovement in this area [18]. About $84 \%$ of mothers agreed that vaccination helps keep their child healthier, while about two-thirds considered it a problem when a child misses 1 or 2 doses (63.6\%) and onethird stated that delaying vaccination was not harmful to their children [7]. Continuous effort of Government and nongovernment organizations to raise community awareness about immunization over the past years undoubtedly has yielded some results. However, more assertive steps are now required to convert this community awareness into a proactive demand for immunization. Community-based service provision through LHWs can help raise awareness about the importance of completing the schedule and improve compliance by mitigating perceived difficulties in accessing the service.

Insufficient management skills, lack of motivation of health workers, inadequate resources and poor monitoring and supervision were also reasons for setback in immunization performance $[7,14,19,20]$. Frequent turnover of district management due to political and other reasons resulted in inexperienced managers with little immunization background. In the absence of continuity of service, organizational experience was lost and managers and vaccinators were not accountable for their performance as supervision and monitoring was not a regular practice. Retaining trained officers at management level for a period long enough to provide managerial experience, creating career pathways to motivate senior field workers and establishing accountability are all required.

Federal resources for EPI include donor support, which is first deposited in the Federal Government account and is then distributed among provinces according to population proportion $[2,9,21]$. This does not help to get critical resources in areas where the programme is most vulnerable. Effective utilization of available resources is another challenge. Moreover, low performance is reducing a significant portion of the investment. Taking 2008 as a baseline, the earmarked budgetary outlay was invested in the programme, although the vaccine utilization was not optimized. If all targeted children were vaccinated, the programme expenditure for each child vaccinated with DPT3 would be US\$17.89 $[9,10]$. However, 
due to failure to reach about $27 \%$ of the targeted children, the actual cost for every vaccinated child was US\$24.51 [10]. In other words, the programme lost benefits of more than US\$28 million of its annual investment in 1 year only. Beside this direct loss, the cost for treatment of diseases incurred by unvaccinated children also added to public expenditure. Half of this direct value loss could be averted if only $10 \%$ more target children could have been vaccinated. In terms of resources, the value lost would have been reduced to US\$20.86 million, US\$ 15.65 million and US\$ 10.43 million by reaching $80 \%, 85 \%$ and $90 \%$ coverage rates, respectively. Just by reaching more children, the programme can not only reach its goal but can also add effectiveness and value to its own investment, which is worth millions of dollars.

With GAVI support, EPI Pakistan added 2 important vaccines to its childhood immunization schedule, introduced new technology and expanded its cold chain capacity and other infrastructure significantly. In terms of volume, the new and underused vaccine support was the largest and most cost intensive. However, direct support to the programme was most critical in building capacity to yield maximum benefits from these new additions. Such direct support needs to be continued by investing HSS support in a way that directly benefits the EPI service delivery capacity and aligns with its indicators, which in turn will enable the programme to increase uptake of new vaccines and thus render more benefits to children. At the same time, reducing the global vaccine price towards an affordable level and a gradual incremental increase in allocation of public resources needs to be ensured for sustaining the new costly additions when GAVI support ends.

EPI Pakistan enjoys the highest level of political and administrative support from the Federal Government as well as from provincial governments. The challenge is to reflect these commitments from the highest level into real achievement by increasing vaccination coverage and thus reducing child mortality.
Some specific actions can be taken to scale-up EPI services in Pakistan: providing regular EPI service through all existing health facilities, establishing an EPI centre in all UCs, redistributing available vaccinators and engaging all skilled manpower, including LHWs, for vaccination could raise community access and compliance to the service and thus raise coverage significantly within a very short time. Along with better access, creating strong public demand for immunization through effective social mobilization and communication strategy, raising motivation of field workers with proper logistics support, incentives and effective supervision and monitoring, coupled with competent management, could definitely enable the programme to reach more children which would in turn add value to the investment for the programme and accentuate further improvement in performance. Being one of the most cost-effective public health interventions, immunization improvement can make significant contribution in Pakistan's achievement of MDG 4 for reduction in child mortality.

\section{References}

1. Coverage evaluation survey 2006. Islamabad, Ministry of Health, Expanded Programme on Immunization, 2007.

2. Planning commission form - 1 (PC-1) 2009-2010 to 2013-2014. Islamabad, Ministry of Health, Expanded Programme on Immunization, 2009.

3. WHO/UNICEF estimate of national immunization coverage 1980-2008, Pakistan. Geneva, World Health Organization, 2009 (http://www.who.int/immunization_monitoring/ en/globalsummary/timeseries/tswucoveragebycountry. cfm?country=PAK, accessed 24 April 2010).

4. Pakistan social \& living standards measurement survey 20042005. Islamabad, Federal Bureau of Statistics, 2005.

5. Pakistan integrated household survey: round 1: 1995-1969. Islamabad, Federal Bureau of Statistics, 1997.

6. Pakistan demographic and health survey 2006-2007. Islamabad, National Institute of Population Studies, 2008.

7. Faisal A et al. Understanding barriers to immunization in Pakistan. Islamabad, Ministry of Health, Expanded Programme on Immunization, 2009.

8. Coverage evaluation survey - Punjab 2003. Lahore, Director General Health Services of Punjab, 2003.
9. WHO/UNICEF joint reporting form 2008, Pakistan. Islamabad, Ministry of Health, Expanded Programme on Immunization, 2009.

10. Comprehensive multi-year plan 2011-2015. Islamabad, Ministry of Health, Expanded Programme on Immunization, 2009.

11. Planning Commission form 7 (PC-1) 2004-05 to 2008-09.. Islamabad, Pakistan, Ministry of Health, Expanded Programme on Immunization, 2004.

12. Immunization coverage data. Islamabad, Ministry of Health, Official Database of the Expanded Programme on Immunization, 2008.

13. Immunization coverage data. Islamabad, Ministry of Health, Official Database of the Expanded Programme on Immunization, 2009.

14. Ahmad $\mathrm{N}$ et al. Immunization coverage in 3 districts of North West Frontier Province (NWFP). Journal of Pakistan Medical Association, 1999, 49(12):301-305.

15. Mansuri FA, Baig LA. Assessment of immunization service in the perspective of both the recipients and the providers: a reflection from focus group discussions. Journal of Ayub Medical College Abbottabad, 2003, 15(1):14-18.

16. Usman HR et al. Determinants of third dose of diphtheriatetanus-pertussis (DTP) completion among children who 
received DTP1 at rural immunization centres in Pakistan: a cohort study. Tropical Medicine \& International Health, 2009, 15(1):140-147.

17. National EPI policy and strategic guidelines. Islamabad, Ministry of Health, Expanded Programme on Immunization, 2005.

18. Siddiqi $\mathrm{N}$ et al. Assessment of EPI (expanded programme of immunization) vaccine coverage in a peri-urban area. Journal of Pakistan Medical Association, 2007, 57(8):391-395.
19. Report on assessment of barriers in immunization services in Pakistan. Pakistan, United Nations Children's Fund, 2004.

20. Mangrio NK, Alam MM, Shaikh BT. Is expanded programme on immunization doing enough? Viewpoint of health workers and managers in Sindh, Pakistan. Journal of Pakistan Medical Association, 2008, 58(2):64-67.

21. Country information fact sheet, Pakistan. GAVI Alliance (http:// www.gavialliance.org/performance/country_results/index. php?countID=52, accessed 10 April 2010). 